\title{
CHEMICAL AND ENERGETIC CHARACTERISTICS OF AFRICAN SWEET SORGHUM AS A SOURCE OF BIOENERGY
}

\author{
José C. Caraschi ${ }^{1}$, Ronaldo da S. Viana ${ }^{2}$, Bruno R. de A. Moreira ${ }^{2}$, Glaucia A. Prates ${ }^{3 *}$ \\ ${ }^{3 *}$ Corresponding author. Universidade Estadual Paulista - UNESP/ Itapeva - SP , Brasil. \\ E-mail: g.prates@unesp.br| ORCID ID: https://orcid.org/0000-0002-8916-3441
}

\section{KEYWORDS}

Green Energy, Bioenergy, Biofuel, Renewable energy.

\begin{abstract}
The aim of this study was to evaluate the energetic potential achieved by the application of phyto-regulators to sweet sorghum cultivars. A randomized complete block design was used. Experiments were conducted using two sweet sorghum cultivars (BRS 508 and BRS 509), four phyto-regulators (ethephon, ethyl-trinexapac, glyphosate, and sulfometuron-methyl), and a control; four replicates were performed 70 days after sowing, at the beginning of the flowering phase of the plants, with the aid of a $\mathrm{CO}_{2}$ pressurized coastal sprayer. The plants were harvested after 40 days, with the stems being cleared at the height of the apical bud, and were subjected to grinding for the extraction of broth. The following analyses were carried out: chemical (total extractives, lignin, and holocellulose contents), proximate (volatile matter, fixed carbon, and ash contents), and energetic (higher heating value). Multiple comparison (Tukey) and linear correlation (Pearson) analyses were carried out at a 5\% significance level. The phyto-regulators positively and significantly influenced the chemical attributes and contents of lignin and fixed carbon. It was concluded that glyphosate, sulfometuron-methyl, and ethephon enhanced the biomass/bioenergy potential of sweet sorghum cultivars.
\end{abstract}

\section{INTRODUCTION}

Originating from the African continent, the genus Sorghum spp. (sorghum) tolerates water deficit and is extremely adaptable to tropical climatic conditions. In addition, the genus is rustic and exhibits high photosynthetic rate and mechanization performance in all its agricultural processes. According to data from Companhia Nacional de Abastecimento (CONAB, Brasil, 2017), the production area of sorghum was 43 million ha worldwide in 2015/2016 and North America was the largest producer globally. The production of sorghum in Brazil reached 2 million tons during the 2016/2017 harvest year. Sorghum, grain, forage, grazing, biomass, and saccharin are fundamental to Brazil's agroeconomic scenario (May et al., 2016). However, rice straw, elephant grass, coffee, corn, coconut fibers, banana, and sisal rachis present high bioenergetic potential (García et al., 2015; Silva et al., 2015).

Sweet sugar broth is commonly used in the production of first-generation ethanol in the sugar energy and micro-distillery industries. Bagasse, straw, and sweet sorghum are partially used in the cellulosic ethanol industry and, occasionally, in the cogeneration of energy in the form of heat or bioelectricity. Therefore, in the absence of any immediate or predetermined application of biomass in the agricultural and/or industrial sectors, its physical volume must be strategically managed for subsequent use with increasingly sustainable technologies, thereby mitigating the negative impacts of the final disposal of waste on the environment (Paula et al., 2011; Faria et al., 2016).

Sorghum bagasse can be reused by means of briquetting, which is a densification technique that adds commercial, ecological, and social value to agroindustrial waste. Compared with wood, briquettes considerably reduce the need for expensive transportation, do not require direct mobilization of forest areas for the extraction of raw material, emit less amounts of greenhouse gases that are harmful to human and animal health, and are approximately five times denser (Amorim et al., 2015).

During their production cycles, agricultural crops undergo numerous quantitative and qualitative changes in their morphophysiological characteristics owing to the contiguous actions of biotic and abiotic factors, such as pests, diseases, weed competition, photoperiod, frost, and temperature and water regime including the timing and duration of cultural practices, such as the application of

\footnotetext{
${ }^{1}$ Universidade Estadual Paulista - UNESP/ Itapeva - SP, Brasil.

${ }^{2}$ Instituição: Faculdade de Ciências Agrárias e Tecnológica, Universidade Estadual Paulista - UNESP/ Dracena - SP, Brasil.

Received in: 7-13-2018
}

Accepted in: 5-28-2019 
phyto-regulators, which can either improve or compromise the raw material quality, thereby directly influencing the energy potential of solid biofuels (May et al. 2016; Viana et al., 2016). Phyto-regulators are synthetic compounds that perform functions analogous to those of plant hormones; despite their benefits, phyto-regulators damage plant physiology and cause reductions in sucrose, lignin, and cellulose contents (Meschede et al. 2011; Viana et al., 2015; Muhwiridzwa et al., 2016).

In Brazil, phyto-regulators classified as inhibitors (glyphosate and sulfometuron-methyl) and retarders (ethephon and ethyl-trinexapac) have been used and tested mainly in sugarcane and sweet sorghum cultivations, and hence there is limited scientific information on the impact of these products on other crops of agronomic interest (Cesarin et al., 2016, Moreira et al., 2018).

The aim of the present study was to evaluate the energetic potential achieved by the application of phytoregulators to sweet sorghum cultivars in terms of their influence on the chemical and energetic properties of the latter.

\section{MATERIAL AND METHODS}

The experiment was carried out at the Paulista Agency of Agribusiness Technology (APTA), Andradina, located in the northwest region of the state of São Paulo, Brazil, at the following geographical coordinates: latitude of $20^{\circ} 55^{\prime} 23^{\prime \prime} \mathrm{S}$, and longitude of $51^{\circ} 23^{\prime} 37^{\prime \prime} \mathrm{W}$. The characteristic climate of the region is Aw, according to the Köppen-Geiger classification, and the soil in the area is dystrophic red-yellow latosol. The seeds of the sweet sorghum cultivars, BRS 508 and BRS 509, were donated by Embrapa-Brazilian Agricultural Research Corporation, Ministry of Agriculture, Livestock, and Food Supply, Corn and Sorghum, located in the municipality of Sete Lagoas, state of Minas Gerais, Brazil.

A randomized complete block design was used: two sweet sorghum cultivars (BRS 508 and BRS 509), four phyto-regulators (ethephon, ethyl-trinexapac, glyphosate, and sulfometuron-methyl) and a control were employed, with four replicates being performed.

After the 70-day interval, at the beginning of the flowering phase of the sorghum cultivars BRS 508 and BRS 509, the phyto-regulators ethephon, ethyl-trinexapac, glyphosate, and sulfometuron-methyl were applied in dosages of $0.07 \mathrm{~L} \cdot \mathrm{ha}^{-1}, \quad 0.05 \mathrm{~L} \cdot \mathrm{ha}^{-1}, \quad 0.08 \mathrm{~L} \cdot \mathrm{ha}^{-1}$, and $0.02 \mathrm{~kg} \cdot \mathrm{ha}^{-1}$, respectively. The phyto-regulators were not applied to the control.

The applications were performed in the morning, from 8:00 a.m. to 11:00 a.m., at a temperature of $25^{\circ} \mathrm{C} \pm$ $2.5^{\circ} \mathrm{C}$ and relative humidity of $70 \% \pm 5 \%$. The phytoregulators were sprayed using a $\mathrm{CO}_{2}$-pressurized sprayer with six flat nozzles (AXI-11002) spaced at intervals of $0.5 \mathrm{~m}$ along the spray boom (Viana et al., 2016). There was no subsequent rainfall.
Forty days after spraying, the cultivars were harvested from three central rows of the experimental plots. After the leaves were removed, the stems were cleared at the height of the apical bud and transported to the Caeté Plant, located in the municipality of Paulicéia, state of São Paulo, for the extraction of broth. The specimens were individually ground in a mechanical hydraulic press, and the bagasse was collected and stored in bags of low-density polyethylene for subsequent laboratory analysis.

Prior to the chemical analysis, the bagasse was defibrated and processed in a Wiley mill. The sawdust obtained was classified in overlapping sieves (40/60 mesh), according to TAPPI T $257 \mathrm{sp} 14$ (TAPPI, 2014).

The biomass specimens of the sweet sorghum cultivars, BRS 508 and BRS 509, treated with phytoregulators, were characterized according to the following analyses: chemical analysis for total extractive content in accordance with TAPPI T 264 cm-87 (TAPPI, 2007), holocellulose content (sodium chlorite method), and lignin content according to TAPPI T 222 om-02 (TAPPI, 2011); proximate analysis for volatile matter content according to the ASTM E872 - 82 standard (ASTM, 2013), ash content according to the ASTM D1102 - 84 standard (ASTM, 2013), and fixed carbon content (determined as the difference between 100 and the sum of percentage moisture, ash, and volatile matter); and energetic analysis for higher heating value (HHV) according to the ASTM D5865 - 04 standard (ASTM, 2013).

The data set was submitted to inferential analysis: normality (Jarque-Bera), analysis of variance (Fisher), multiple comparisons (Tukey), and linear correlation (Pearson), each at the 5\% significance level. In addition, the dispersion measures, such as mean and standard deviation, were determined. To interpret the magnitude of the correlation coefficient, Figueiredo Filho \& Silva Junior (2010) suggested the following scores: $0.1 \leq \mathrm{r}<0.3$ (weak); $0.3 \leq \mathrm{r}<0.7$ (moderate); and $0.7 \leq \mathrm{r}<1.0$ (strong), in which " $r$ " is the correlation coefficient. We adapted this methodology for more careful deductions, and employed the following stratified scores in the case of Pearson's correlation coefficient: $0.1 \leq \mathrm{r}<0.3$ (negligible); $0.3 \leq \mathrm{r}<$ 0.5 (weak); $0.5 \leq \mathrm{r}<0.7$ (median); $0.7 \leq \mathrm{r}<0.9$ (strong); and $0.9 \leq \mathrm{r}<1.0$ (very strong). The statistical software used was Software R version 3.3.1. (R Core Team, 2017).

\section{RESULTS AND DISCUSSION}

The results obtained in the chemical-energetic characterization of the biomass specimens of the sweet sorghum cultivars, BRS 508 and BRS 509, with and without the application of phyto-regulators are presented in Table 1. 
TABLE 1. Chemical-energetic characterization of sweet sorghum biomass cultivars, BRS 508 and BRS 509, with and without application of phyto-regulators.

\begin{tabular}{|c|c|c|c|c|c|c|c|}
\hline \multirow[t]{2}{*}{ Analysis } & \multicolumn{3}{|c|}{$\begin{array}{l}\text { Chemical }^{1} \\
(\%)\end{array}$} & \multicolumn{2}{|c|}{$\begin{array}{l}\text { Proximate } \\
(\%)\end{array}$} & \multirow{2}{*}{\multicolumn{2}{|c|}{$\begin{array}{c}\begin{array}{l}\text { Energetic }^{3} \\
\left(\mathrm{MJ} \cdot \mathrm{kg}^{-1}\right)\end{array} \\
\mathrm{HHV}\end{array}$}} \\
\hline & Lig & Hol & Ex & Ash & $\mathrm{FC}$ & & \\
\hline Cultivar & \multicolumn{7}{|c|}{ BRS 508} \\
\hline Control & 9.78 & 62.72 & 27.50 & 2.65 & 18.25 & 79.10 & 18.42 \\
\hline Glyphosate & 14.95 & 68.12 & 16.93 & 2.96 & 19.60 & 77.44 & 18.62 \\
\hline Sulf.-methyl & 15.71 & 57.03 & 27.26 & 3.35 & 19,04 & 77.61 & 18.61 \\
\hline Ethephon & 10.12 & 52.62 & 37.26 & 2.60 & 18,29 & 79.11 & 18.57 \\
\hline Ethyl-trinexapac & 11.20 & 59.80 & 29.00 & 2.65 & 18.27 & 79.08 & 18.50 \\
\hline Mean & 12.35 & 60.06 & 27.59 & 2.84 & 18.69 & 78.47 & 18.54 \\
\hline Standard deviation & 5.84 & 2.78 & 7.23 & 0.32 & 0.61 & 0.86 & 0.08 \\
\hline Cultivar & \multicolumn{7}{|c|}{ BRS 509} \\
\hline Control & 8.82 & 53.04 & 38.14 & 2.68 & 18.21 & 79.11 & 18.53 \\
\hline Glyphosate & 12.83 & 59.64 & 27.53 & 2.81 & 20.26 & 76.93 & 18.70 \\
\hline Sulf.-methyl & 13.57 & 57.20 & 29.23 & 2.84 & 19.76 & 77.40 & 18.54 \\
\hline Ethephon & 10.67 & 52.94 & 36.39 & 2.74 & 19.49 & 77.77 & 18.56 \\
\hline Ethyl-trinexapac & 12.14 & 58.25 & 29.61 & 2.87 & 18.22 & 78.91 & 18.51 \\
\hline Mean & 11.61 & 56.21 & 32.18 & 2.79 & 19.19 & 78.02 & 18.57 \\
\hline Standard deviation & 3.07 & 1.89 & 4.75 & 0.08 & 0.93 & 0.95 & 0.08 \\
\hline
\end{tabular}

(1) Chemical composition: lignin content (Lig), holocellulose content (Hol), total extractive content (Ex); (2) Proximate analysis: ash content (Ash), fixed carbon content (FC), volatile matter content (VM); and (3) Energetic analysis: higher heating value (HHV).

The analysis of variance and multiple comparisons of the ash contents are presented in Table 2 .

TABLE 2. Residual ash content (\%) of sweet sorghum biomass cultivars, BRS 508 and BRS 509, managed with phyto-regulators.

\begin{tabular}{|c|c|c|c|c|c|c|c|}
\hline \multirow{2}{*}{ Cultivar } & \multicolumn{7}{|c|}{ Phyto-regulator } \\
\hline & $\mathrm{C}$ & G & S-m & $\mathrm{E}$ & E-t & Mean & F Test \\
\hline BRS 508 & $2.65 \mathrm{BC}$ & $2.96 \mathrm{~B}$ & $3.35 \mathrm{aA}$ & $2.60 \mathrm{C}$ & $2.65 \mathrm{BC}$ & 2.84 & $12.38^{*}$ \\
\hline BRS 509 & 2.68 & 2.81 & $2.84 \mathrm{~b}$ & 2.74 & 2.87 & 2.79 & $0.76^{\mathrm{ns}}$ \\
\hline Mean & 2.66 & 2.90 & 3.10 & 2.67 & 2.76 & & \\
\hline F test & $0.02^{\mathrm{ns}}$ & $1.44^{\mathrm{ns}}$ & $16.25^{*}$ & $1.17^{\mathrm{ns}}$ & $2.99^{\mathrm{ns}}$ & & \\
\hline \multicolumn{8}{|c|}{ F test phyto-regulator $=7.94^{*}$} \\
\hline \multicolumn{8}{|c|}{$\mathrm{F}$ test cultivar $=1.02^{\mathrm{ns}}$} \\
\hline \multicolumn{8}{|c|}{ F test phyto-regulator $\mathrm{x}$ cultivar $=5.21^{*}$} \\
\hline \multicolumn{8}{|c|}{ Variation coefficient $=6.38$} \\
\hline
\end{tabular}

Mean values followed by the same letter in upper case in the row and in lower case in the column, do not differ, based on the Tukey test (p < $0.05) ; p$-value $=0.24 ;$ *significant based on Fisher's test $(\mathrm{p}<0.05)$; control $(\mathrm{C})$, glyphosate $(\mathrm{G})$, sulfometuron-methyl $(\mathrm{S}-\mathrm{m})$, ethephon $(\mathrm{E})$, and ethyl-trinexapac (E-t).

At the cultivar level, the BRS 508 biomass treated with sulfometuron-methyl showed significantly higher ash content than that of BRS 509. There was no significant difference between the two cultivars in terms of other treatments.

As revealed by the analysis of variance, at the BRS 509 cultivar level, there was no rejection of the null hypothesis among the specimens treated with the phytoregulators. However, the plants sprayed with ethyltrinexapac, sulfometuron-methyl, glyphosate, and ethephon had, on average, $8 \%, 6 \%, 5 \%$, and $3 \%$, respectively, more residual ash compared to that of the control. Among the
BRS 508 cultivar specimens, the use of sulfometuronmethyl increased the ash content of the raw material by $20 \%$ in comparison to that of the control, and this increase was statistically significant.

Excessive presence of ash in agroindustrial waste can promote corrosion and mechanical wear in equipment by abrasion as well as compromise the heat transfer zones of carbon steel metal sheets, especially in high-temperature furnaces, and this is even more critical when solid biofuels are derived from biomass with ash content exceeding $4 \%$ (Shenglei et al., 2014). 
The applications of sulfometuron-methyl and glyphosate to BRS 508 and of ethyl-trinexapac to BRS 509 partially limited the energy generation potential of these raw materials, as these treatments were associated with the highest ash percentages of $3.35 \%, 2.96 \%$, and $2.87 \%$, respectively. The situation became even more restrictive in the case of the BRS 508 bagasse treated with sulfometuronmethyl, because, according to Gravalos et al. (2016), plant biomasses are considered suitable for the production of solid biofuels when their ash contents are less than 3\% (Carvalho et al., 2015). The BRS 508 biomass treated with ethephon exhibited a lower percentage of ash mass, which legitimized the synergic effect of this phyto-regulator in terms of ash content.

The analysis of variance and multiple comparisons of the volatile matter contents of the specimens are presented in Table 3.

TABLE 3. Volatile matter content (\%) of sweet sorghum biomass cultivars, BRS 508 and BRS 509, treated with phyto-regulators.

\begin{tabular}{llllllll}
\hline \multirow{2}{*}{ Cultivar } & \multicolumn{7}{c}{ Phyto-regulator } \\
\cline { 2 - 8 } & C & G & S-m & E & E-t & Mean & F test \\
\hline BRS 508 & $79.10 \mathrm{~A}$ & $77.44 \mathrm{aB}$ & $77.60 \mathrm{~B}$ & $79.11 \mathrm{aA}$ & $79.08 \mathrm{~A}$ & 79.47 & $94.79^{*}$ \\
BRS 509 & $79.11 \mathrm{~A}$ & $76.93 \mathrm{bC}$ & $77.40 \mathrm{~B}$ & $77.77 \mathrm{bB}$ & $78.91 \mathrm{~A}$ & 78.02 & $114.73^{*}$ \\
Mean & 79.10 & 77.18 & 77.50 & 78.44 & 79.00 & & \\
F test & $0.01^{\mathrm{ns}}$ & $16.56^{*}$ & $2.54^{\mathrm{ns}}$ & $114.30^{*}$ & $1.78^{\mathrm{ns}}$ &
\end{tabular}

$\mathrm{F}$ test phyto-regulator $=191.23^{*}$

F test cultivar $=62.04^{*}$

F test phyto-regulator $\mathrm{x}$ cultivar $=18.29^{*}$

Variation coefficient $=0.23$

Mean values followed by the same letter, in upper case in the row and in lower case in the column, do not differ, based on the Tukey test ( $\mathrm{p}<$

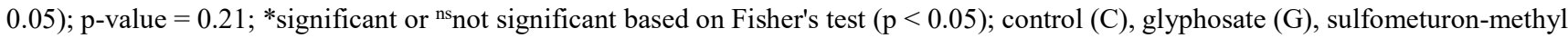
(S-m), ethephon (E), and ethyl-trinexapac (E-t).

Among the BRS 508 cultivar specimens, those treated with ethephon and ethyl-trinexapac, as well as the control, exhibited the highest volatile matter content with no significant difference between them. By contrast, the biomass of the plants treated with sulfometuron-methyl and glyphosate were associated with lower volatile matter contents. All phyto-regulators barring ethephon reduced the volatile matter content of the feedstock; the reductions achieved by using ethyl-trinexapac, sulfometuron-methyl, and glyphosate were approximately $0.03 \%, 1.9 \%$, and $2.1 \%$, respectively, compared to the control.

Among the BRS 509 cultivar specimens, the plants treated with ethyl-trinexapac exhibited significantly higher volatile matter than those treated with ethephon, sulfometuron-methyl, and glyphosate. The applications of ethyl-trinexapac, ethephon, sulfometuron-methyl, and glyphosate promoted reductions of $0.25 \%, 2.16 \%, 1.70 \%$, and $2.76 \%$, respectively, in the volatile matter content of the bagasse compared to that of the control.
In evaluating the performance of the cultivars treated with the same phyto-regulators, no significant difference was found between the volatile matter contents of the control groups of the two cultivars. However, the BRS 508 plants treated with glyphosate and ethephon presented significantly higher volatile matter contents than those of the BRS 509 plants with identical treatments.

According to Brand (2010), the volatile matter contents of the main agricultural and forestry residues with the potential to generate renewable energy vary in the range $75-85 \%$, and this authenticates the results obtained in the present study. According to Shenglei et al. (2014), the higher the volatile matter content, the lower the reactivity and ignition of the raw material. Therefore, the BRS 508 and BRS 509 plants submitted to glyphosate, sulfometuronmethyl, and ethephon applications showed the highest values of volatile matter content among all the specimens.

The analysis of variance and multiple comparisons of the fixed carbon contents of the specimens are presented in Table 4. 
TABLE 4. Fixed carbon content (\%) of sweet sorghum biomass cultivars, BRS 508 and BRS 509, managed with phyto-regulators.

\begin{tabular}{|c|c|c|c|c|c|c|c|}
\hline \multirow{2}{*}{ Cultivar } & \multicolumn{7}{|c|}{ Phyto-regulator } \\
\hline & $\mathrm{C}$ & G & S-m & $\mathrm{E}$ & E-t & Mean & F test \\
\hline BRS 508 & $18.25 \mathrm{~B}$ & $19.60 \mathrm{bA}$ & $19.04 \mathrm{bA}$ & $18.29 \mathrm{bB}$ & $18.27 \mathrm{~B}$ & 18.27 & $23.98^{*}$ \\
\hline BRS 509 & $18.21 \mathrm{C}$ & $20.26 \mathrm{aA}$ & $19.76 \mathrm{aB}$ & $19.49 \mathrm{aA}$ & $18.22 \mathrm{C}$ & 19.19 & $64.34^{*}$ \\
\hline Mean & 18.23 & 19.93 & 19.40 & 18.89 & 18.24 & & \\
\hline F test & $0.03^{\mathrm{ns}}$ & $22.40^{*}$ & $18.94^{*}$ & $53.94^{*}$ & $0.10^{\mathrm{ns}}$ & & \\
\hline \multicolumn{8}{|c|}{ F test phyto-regulator $=77.14^{*}$} \\
\hline \multicolumn{8}{|c|}{ F test cultivar $=50.72^{*}$} \\
\hline \multicolumn{8}{|c|}{$\mathrm{F}$ test phyto-regulator $\mathrm{x}$ cultivar $=11.17^{*}$} \\
\hline \multicolumn{8}{|c|}{ Variation coefficient $=1.22$} \\
\hline
\end{tabular}

Mean values followed by the same letter, in upper case in the row and in lower case in the column, do not differ, based on the Tukey test ( $\mathrm{p}<$ $0.05)$; $\mathrm{p}$-value $=0.28$; ${ }^{*}$ significant or ${ }^{\mathrm{ns}}$ not significant based on Fisher's test $(\mathrm{p}<0.05)$; control $(\mathrm{C})$, glyphosate $(\mathrm{G})$, sulfometuron-methyl (S-m), ethephon (E), and ethyl-trinexapac (E-t).

In the case of the BRS 508 cultivar, the bagasse from the plants submitted to sprays of glyphosate and sulfometuron-methyl showed significantly higher fixed carbon contents than those of the plants subjected to the other treatments, and the latter did not exhibit statistically significant differences. Compared to the control, the applications of glyphosate, sulfometuron-methyl, ethephon, and ethyl-trinexapac provided increases of $7.4 \%, 4.4 \%$, $0.2 \%$, and $0.2 \%$, respectively, in the fixed carbon content of the biomass.

A similar trend was observed in the specimens of the BRS 509 cultivar, in which the fixed carbon content of the bagasse from the plants treated with glyphosate was significantly higher than those from the plants treated with sulfometuron-methyl, ethyl-trinexapac, and ethephon as well as the control. Compared to the control, the fixed carbon contents of the biomass of the BRS 509 cultivar specimens increased by $11.26 \%, 8.51 \%, 7.03 \%$, and $0.05 \%$, with the application of glyphosate, sulfometuron-methyl, ethephon, and ethyl-trinexapac, respectively.
In evaluating the performance of the cultivars treated with the same phyto-regulators, it was observed that the fixed carbon content of the BRS 509 bagasse was significantly higher than that of BRS 508 bagasse in the cases of applications of glyphosate, sulfometuron-methyl, and ethephon. The results obtained agree with the data presented by Brand (2010), Williams et al. (2012), Protásio et al. (2013), and Chen et al. (2015) who mention in their respective researches that the fixed carbon indices of agricultural and forest lignocellulosic residues are in the range $14-30 \%$.

Given that biomass with higher fixed carbon content and lower concentration of volatile matter has a greater propensity to generate briquettes and pellets with higher heating value, the potential of glyphosate-treated BRS 509 sweet sorghum biomass, which is associated with higher fixed carbon content and lower volatile matter content, is validated.

The analysis of variance and multiple comparisons of the HHVs of the two cultivars are presented in Table 5.

TABLE 5. Higher heating value (MJ.kg-1) of sweet sorghum biomass cultivars, BRS 508 and BRS 509, managed with phyto-regulators.

\begin{tabular}{lllllll}
\hline \multirow{2}{*}{ Cultivar } & \multicolumn{5}{c}{ Phyto-regulator } \\
\cline { 2 - 7 } & $\mathrm{C}$ & $\mathrm{G}$ & $\mathrm{S}-\mathrm{m}$ & $\mathrm{E}$ & $\mathrm{E}-\mathrm{t}$ & Mean \\
\hline BRS 508 & 18.42 & 18.62 & 18.61 & 18.57 & 18.50 & $18,55 \mathrm{~b}$ \\
BRS 509 & 18.53 & 18.70 & 18.54 & 18.56 & 18.51 & $18,65 \mathrm{a}$ \\
Mean & $18.49 \mathrm{~B}$ & $18.68 \mathrm{~A}$ & $18.66 \mathrm{~A}$ & $18.64 \mathrm{~A}$ & $18.52 \mathrm{~B}$ & \\
F test phyto-regulator $=77.14^{*}$ & & & & & \\
F test cultivar = 39.48* & & & & & \\
F test phyto-regulator & & & & & \\
Variation coefficient $=0.26$ & & & & &
\end{tabular}

Mean values followed by the same letter, in upper case in the row and in lower case in the column, do not differ based on the Tukey test ( $\mathrm{p}<$ $0.05)$; $\mathrm{p}$-value $=0.66$; *significant or ${ }^{\mathrm{ns}}$ not significant based on Fisher's test $(\mathrm{p}<0.05)$; control $(\mathrm{C})$, glyphosate $(\mathrm{G})$, sulfometuron-methyl (S-m), ethephon (E), and ethyl-trinexapac (E-t). 
As indicated by the analysis of variance, there was no rejection of the null hypothesis at the level of interaction between the factors, with significant differences appearing only at the level of simple effects. The applications of the phyto-regulators, glyphosate, sulfometuron-methyl and ethephon, endowed the biomass of the cultivars with the highest values of $\mathrm{HHV}$, and differed significantly from the treatments involving ethyl-trinexapac and the control, which were statistically indifferent. At the cultivar level, the HHV of the bagasse of BRS 509 was significantly higher than that of BRS 508 .
To evaluate the energy potential of agricultural lignocellulosic residues for the production of briquettes and pellets, it is noteworthy that, on average, the biomass specimens presented HHVs in the range 17-18 $\mathrm{MJ} \cdot \mathrm{kg}^{-1}$.

Although there was no interaction between the factors, the phyto-regulators positively and significantly influenced the HHV of sweet sorghum bagasse, maintaining it above the international quality standard corresponding to $16.50 \mathrm{MJ} \cdot \mathrm{kg}^{-1}$, as recommended by the ISO $17225-1$ standard (ISO, 2014) for the production of briquettes and pellets from agricultural and forest residues. The results of the Pearson correlation matrix are presented in Table 6.

TABLE 6. Coefficients of linear associations between the chemical-energetic attributes of sweet sorghum biomass of BRS 508 and BRS 509 cultivars managed with phyto-regulators, aiming at energy production.

\begin{tabular}{|c|c|c|c|c|c|c|}
\hline Parameter $^{(1)}$ & Hol & Ext & ASH & VM & $\mathrm{FC}$ & HHV \\
\hline Lig & $0.44^{*}$ & $-0.72^{*}$ & $0.69^{*}$ & $-0.70^{*}$ & $0.54^{*}$ & $0.42^{*}$ \\
\hline Hol & & $-0.94^{*}$ & $0.18^{\mathrm{ns}}$ & $-0.23^{\mathrm{ns}}$ & $0.17^{\mathrm{ns}}$ & $-0.14^{\mathrm{ns}}$ \\
\hline Ext & & & $-0.39^{*}$ & $0.44^{*}$ & $-0.33^{*}$ & $-0.04^{\mathrm{ns}}$ \\
\hline Ash & & & & $-0.45^{*}$ & $0.18^{\mathrm{ns}}$ & $0.32^{\mathrm{ns}}$ \\
\hline VM & & & & & $-0.96^{*}$ & $-0.82^{*}$ \\
\hline $\mathrm{FC}$ & & & & & & $0.82^{*}$ \\
\hline
\end{tabular}

*Significant and ${ }^{\mathrm{ns}}$ not significant, based on the Pearson test $(\mathrm{p}<0.05)$; lignin (Lig), holocellulose (Hol), total extractives (Ex), ash $($ Ash $)$, volatile matter (VM), fixed carbon (FC), higher heating value (HHV).

Among the most important associations was that of volatile matter content and $\mathrm{HHV}$, which correlated negatively with a strong degree of linear association, indicating that the presence of volatile matter proportionally reduced the calorific values of the biomass of the BRS 508 and BRS 509 sorghum cultivars.

According to ISO 17225-1 (ISO, 2014), the biological basis of the inverse correlation between volatile material content and HHV is the fact that volatile materials are inert compounds, i.e., unlike fixed carbon, they do not actively participate in the combustion of plant biomass. These results, besides confirming the reports of Vinutha et al. (2014), justified the lower HHV values presented by the BRS 508 and BRS 509 controls, and the specimens treated with ethyl-trinexapac (BRS 508), ethephon (BRS 508), and ethyl-trinexapac (BRS 509), since these were associated with the highest volatile matter contents (Table 3 ).

The attributes, fixed carbon and HHV, exhibited a positive correlation with a strong degree of linear association, suggesting that the higher the mass percentage of organic carbon, the greater the energy potential of sorghum bagasse; this explains the significant energy yield of the bagasse of the BRS 509 cultivar submitted to the applications of glyphosate and ethephon.

Among the elemental components of biomass, i.e., lignin, holocellulose, and total extractives, only lignin showed a significant correlation with $\mathrm{HHV}$, indicating that value of the raw materials of the cultivars increases with lignin content. It is believed that in comparison with cellulose and hemi-cellulose, lignin content increases the HHV of biomass (Demirbas, 2001; Jung et al., 2015) owing to the high contents of carbon and hydrogen atoms present in its molecular composition, since these are the main chemical elements responsible for the generation of energy. The nature of this correlation justified the highest values of HHV exhibited by the plants treated with applications of glyphosate (BRS 508), glyphosate (BRS 509), and sulfometuron-methyl (BRS 509), as these specimens were associated with the highest percentages of total lignin, as described in Table 7.

TABLE 7. Linear correlation of chemical-energetic biomass parameters for the production of solid biofuels.

\begin{tabular}{llll}
\hline Parameter & Ash & Fixed Carbon & HHV \\
\hline Volatile matter & -0.57 & 0.26 & 0.24 \\
Ash & & -0.94 & -0.89 \\
Fixed Carbon & & & 0.96 \\
\hline
\end{tabular}


Understanding the degrees of linear associations between the physical, chemical, and energetic attributes of the raw materials is fundamental to the development of technologies for the production of solid biofuels, such as briquettes and pellets, because this information enables the definition of agronomic strategies pertaining to plant physiology, genetics, and mineral nutrition of energy crops to improve the technical, economic, environmental, industrial, commercial, and social aspects of the raw materials and, above all, enhance their sustainability.

\section{CONCLUSIONS}

The main conclusions that may be drawn from the present study on the heating calorific values of different sweet sorghum biomass for combustion are listed below:

- The energy yield of BRS 509 sorghum cultivar was higher than that of BRS 508 .

- The phyto-regulators, glyphosate, sulfometuronmethyl, and ethephon, significantly increased the HHVs of the cultivars BRS 509 and BRS 508.

- The fixed carbon and lignin contents of the sweet sorghum biomass showed positive correlations with HHV.

\section{REFERENCES}

ASTM - American Society For Testing And Materials (2013) ASTM D1102 - 84: standard test method for ash in wood. ASTM International, West Conshohocken.

ASTM - American Society For Testing And Materials (2013) ASTM D5865 - 04: standard test method for gross calorific value of coal and coke. ASTM International, West Conshohocken.

ASTM - American Society For Testing And Materials (2013) ASTM E872 - 82: standard test method for volatile matter in the analysis of particulate wood fuels. ASTM International, West Conshohocken.

Amorim FS, Ribeiro MX, Protásio TP, Borges CHA, Costa RMC (2015) Production of briquettes from forest species. Green Magazine on Agroecology and Sustainable Development 10(4):34-41.

Brand MA (2010) Energia de Biomassa Florestal. Rio de Janeiro, Editora Interciência, 131p.

Cesarin E, Carrega WCE, Martins PFRB, Amaral CAL, Nepumuceno MP, Alves PLDCA (2016) Consequence of different ripeners on germination and initial growth of morning glory. African Journal of Agricultural Research 11(42):4214-4221.

Brasil (2017) Ministério da Agricultura. Companhia Nacional de Abastecimento. CONAB. Conjuntura Mensal. Accessed: April 03, 2019.

Carvalho DM, Sevastyanova O, Penna LS, Silva BP, Lindström ME, Colodette JL (2015) Assessment of chemical transformations in eucalyptus, sugarcane bagasse and straw during hydrothermal, dilute acid, and alkaline pretreatments. Industrial Crops and Products 73:118-126.

Chen W-H, Peng J, Bi XT (2015) A state-of-the-art review of biomass torrefaction, densification and applications. Renewable and Sustainable Energy Reviews 44:847-866.
Demirbas A (2001) Relationships between lignin contents and heating values of biomass. Energy Conversion \& Management 42:183-188.

Faria WS, Protásio TP, Trugilho PF, Pereira BLC, Carneiro ACO, Carlos Rogério Andrade CR, Guimarães Junior JB (2016) Transformation of lignocellulosic waste of coffee into pellets for thermal power generation. Coffee Science 11(1):137-147.

Figueiredo Filho DB, Silva Junior JA (2010) Desvendando os mistérios do coeficiente de correlação de Pearson (r). Revista Política Hoje 18(1):115-146.

García R, Pizarro C, Álvarez A, Lavín AG, Bueno JL (2015) Study of biomass combustion wastes. Fuel 148(12):152-159.

Gravalos I, Xyradakis P, Kateris D, Gialamas T, Bartzialis D, Giannou K (2016) An experimental determination of gross calorific value of different agroforestry species and bio-based industry residues. Natural Resources 7(1):57-68.

ISO - International Organization Standardization (2014) ISO 17225-1: Solid biofuels - Part 1 - General requirements. Brussels, ISO.

Jung SJ, Kim S-H, Chung I-H (2015) Comparison of lignin, cellulose, and hemicellulose contents for biofuels utilization among 4 types of lignocellulosic crops. Biomass and Bioenergy 83:322-327

May A, Souza VF, Gravina GA, Fernandes PG (2016) Plant population and row spacing on biomass sorghum yield performance. Ciência Rural 46(3):434-39. DOI: http://dx.doi.org/10.1590/0103-8478cr20141133

Meschede DK, Velini ED, Carbonari, CA, Silva JRM (2011) Physiological alteration in sugarcane influenced by glyphosate and sulfometuron-methyl application. Planta Daninha 29(2):413-419.

Moreira BRA, Cunha MO, Mateus GP, Viana RS (2018) Technological profile of sweet sorghum cv. cmsxs-646 juice submitted to chemical ripeners application and sampling periods. Revista Brasileira de Milho e Sorgo 17(3):420-430. DOI: http://dx.doi.org/10.18512/19806477/rbms.v17n3p420-430

Muhwiridzwa M. Manenji BT, Madanzi T, Mahohoma W (2016) Evaluating the effects of chemical ripening with fluazifop-p-butyl on sugarcane (Saccharum officinarum L.) yield and sugar content. International Journal of Plant \& Soil Science 9(6):1-8.

Paula LER, Trugilho PF, Rezende RN, Assis OC, Baliza AER (2011) Production and evaluation of lignocellulosic waste briquettes. Brazilian Forest Research 31(66):103-112.

Protásio TP, Bufalino L, Tonoli GHD, Guimarães Junior M, Trugilho PF, Mendes LM (2013) Brazilian lignocellulosic wastes for bioenergy production: characterization and comparison with fossil fuels. BioResources 8(1):1166-1185. 
R Core Team (2017) R: a language and environment for statistical computing. Available: https: //www.R-project.org/

Shenglei Du S, Yang H, Qian K, Wang X, Chen H (2014) Fusion and transformation properties of the inorganic components in biomass ash. Fuel 117:1281-1287. DOI: http://dx.doi.org/10.1016/j.fuel.2013.07.085

Silva DA, Nakashima GT, Barros JL, Roz AL, Yamaji FM (2015) Caracterização de biomassas para a briquetagem. Floresta 45(4):713-722.

TAPPI - Technical Association of the Pulp and Paper Industry (2011) TAPPI T 222 om-02: Acid - insoluble lignin in wood and pulp. Atlanta, TAPPI Press.

TAPPI - Technical Association of the Pulp and Paper Industry (2014) TAPPI T 257 sp 14: Sampling and preparing wood for analysis. Atlanta, TAPPI Press.

TAPPI - Technical Association of the Pulp and Paper Industry (2007) TAPPI T $264 \mathrm{~cm}-97$ : preparation of wood for chemical analysis. Georgia, TAPPI Press.
Viana RS, Figueiredo PAM, Lisboa LAM, Assumpção ACND, Sá ME, May A (2015) Application of chemical growth regulators on the technological quality of sweet sorghum cv. Biomatrix 535. Revista Brasileira de Milho e Sorgo 14(3):326-34.

Viana RS, Figueiredo PAM, Lisboa LAM, Magalhães AC (2016) Morphoanatomical aspects and technological quality of saccharine sorghum submitted to plant regulators. Revista Brasileira de Herbicidas 15(2):184-194.

Vinutha KS, Rayaprolu L, Yadagiri K, Umakanth AV, Patil, JV, Rao PS (2014) Sweet sorghum research and development in Índia: Status and prospects. Sugar Tech 16(2):133-143.

Williams A, Jones JM, Pourkashanian M (2012) Pollutants from the combustion of solid biomass fuels. Progress in Energy and Combustion Science 38(2):113-137. 